\title{
THE WILD WEST IS WILD: THE HOMICIDE RESOURCE CURSE
}

\author{
Mathieu Couttenier \\ University of Geneva
}

\author{
Pauline Grosjean \\ School of Economics, \\ University of New South Wales, \\ and Australian School of Business
}

\author{
Marc Sangnier \\ Aix-Marseille University (Aix-Marseille \\ School of Economics), CNRS and \\ EHESS
}

\begin{abstract}
We document interpersonal violence as a dimension of the resource curse. We rely on a historical natural experiment in the United States, where mineral discoveries occurred sometimes before, sometimes after formal institutions were established in the county of discovery. In places where mineral discoveries occurred before formal institutions were established, there were more homicides per capita historically and the effect has persisted to this day. Today, the share of homicides and assaults explained by the historical circumstances of mineral discoveries is comparable to the effect of education or income. Our results imply that short-term and quasi-exogenous variations in the institutional environment can lead to large and persistent differences in cultural and institutional development. (JEL: K42, N31, O14, Z13)

"It is manifest that during the time men live without a common power to keep them all in awe, they are in that condition which is called war; and such a war, as is of every man, against every man. [...] The nature of war consisteth not in actual fighting

The editor in charge of this paper was Nicola Gennaioli.

Acknowledgments: We are very grateful to the editor, Nicola Gennaioli, and four anonymous referees, as well as Daron Acemoglu, Quamrul Ashraf, Sam Bowles, Ann Carlos, Karen Clay, Paul Castaneda Dower, Oded Galor, Stephanie Moussalli, Suresh Naidu, Francisco Pino, Pascual Restrepo, Estefania SantacreuVasut, Guido Tabellini, Nico Voigtlaender, Gavin Wright, as well as participants of the NBER Summer Institute 2014 (Income Distribution and Macroeconomics), AEA 2014, ESEM 2014, the 2014 Santa Fe Institute meeting on the coevolution of behavior and institutions, Barcelona GSE Summer Forum 2013, and ISNIE 2013 meetings, and seminar audiences at the Geneva Graduate Institute of International and Development Studies, Bocconi University, University of Cergy-Pontoise, Goethe University in Frankfurt, Queensland University of Technology, Tilburg University, University of New South Wales, University of Otago, University of Victoria, and University of Fribourg for helpful comments and suggestions. We thank four anonymous referees and the editor for their especially insightful comments. We thank Dan Berkowitz, Karen Clay, and Dietrich Vollrath for sharing data with us and the Swiss National Fund for the research.

E-mail: mathieu.couttenier@unige.ch (Couttenier); p.grosjean@unsw.edu.au (Grosjean); marc.sangnier@univ-amu.fr (Sangnier)
\end{abstract}


but in the known disposition thereto, during all the time there is no assurance to the contrary."

(Thomas Hobbes, Leviathan (1651), p. 262)

\section{Introduction}

The way in which natural resource endowments shape short- and long-run economic and political outcomes has been the subject of a vast literature. ${ }^{1}$ In particular, natural resource windfalls have been shown to have a negative and persistent influence on economic outcomes and institutional quality-the so-called resource curseparticularly when they occur in the context of weakly institutionalized polities as highlighted by Mehlum et al. (2006). More recently, various studies have focused on violence as a particular aspect of the resource curse. For example, variations in natural resource endowments or prices have been associated with a higher prevalence of violence in Africa (Lei and Michaels 2014; Berman et al. 2015), in Colombia (Dube and Vargas 2013), in Peru (Aragón and Rud 2013), in Mexico (Castillo et al. 2014), and in the Democratic Republic of Congo (Sánchez de la Sierra 2015). All of these studies deal with contexts in which the state is weak or absent and conclude that natural resources lead to violence by organized groups such as warlords, drug gangs, or rebel groups. This violent curse is persistent, as suggested by Buonanno et al. (2015) who report that the Sicilian Mafia originated from 19th century commodity price shocks.

In this paper, we take advantage of the variation in the relative timings of state development and mineral discoveries in the United States to study how the relationship between mineral resources and interpersonal violence is conditioned by state development at the time of resources discoveries.

The circumstances of mineral discoveries in the United States provide an ideal natural experiment to examine this relationship. Mineral exploration in the United States was the result of private and intense efforts, which were fueled by a legal specificity of the United States where minerals are private property. The territorial expansion of the US government was driven by geopolitical factors, which were orthogonal to mineral discoveries according to Davis et al. (1972), even when the two processes occurred at the same time, such as in the West of the United States in the second half of the 19th century. As a result, some mineral deposits were discovered before formal institutions were established, whereas others were discovered after.

The Mineral Resources Data System (MRDS) provides information on the location and date of discovery of more than 17,500 mineral discoveries in the contiguous United States since the 17th century. The Atlas of Historical County Boundaries, which documents the creation of (and subsequent changes in) the boundaries of administrative units in the United States, enables us to assess whether each discovery occurred before or after the state was established at the very place where minerals are located. We then

1. See, among others, Engerman and Sokoloff (1997, 2002), Rajan (2009), and Brollo et al. (2013). See also Torvik (2009) for a review of the literature. 
map this information into present-day counties and we record how many discoveries within a given county's physical boundaries occurred pre- or post-statehood, that is, in the absence or in the presence of formal institutions. This variation allows us to examine how the relationship between mineral resources and violence is moderated by the quality of formal institutions using both historical and contemporary measures of interpersonal violence.

We first use panel data on homicides for 63 counties across 10 states from 1790 to 1900 to show that new discoveries have a positive and statistically significant effect on violence, but only in counties that experienced some discoveries prior to state development. We then rely on 2000 county-level violent crimes data to document the long-lasting and positive association between pre-statehood discoveries and interpersonal violence. In contrast, post-statehood discoveries are not significantly associated with today's violence. We find that a one standard deviation increase in the number of pre-statehood mineral discoveries is associated with an increase in today's rate of violent crimes (homicides, assaults, and aggravated assaults) by around $4 \%$ of the standard deviation. This figure turns out to be very close to the effects of more traditional determinants of violence such as education and income.

To the best of our knowledge, our findings document for the first time the existence of a homicide resource curse, which, like other resource curses, is conditional on the quality of initial institutions. Most existing studies have focused on organized forms of violence by rebel groups, warlords, drug gangs, or mafia families, who fill the void of a weak or absent state. In contrast, our focus is on interpersonal violence. Our finding that the homicide resource curse hinges on the absence of third-party enforcement is consistent with Elias' (1994) civilizing process, which links the secular decline in homicides to the development of a strong state that enforces contracts and monopolizes violence. More recently, Pinker (2011) has described the steady decline in European homicides since the emergence of modern states in the Middle Ages. In sharp contrast with this view, other scholars have argued that self-interest can suffice to sustain a peaceful order, even in anarchy. In "The Not So Wild, Wild West: Property Rights on the Frontier", Anderson and Hill argue that this was demonstrated by the private enforcement of property rights in the West of the United States in the 19th century. However, our findings and those offered by historical studies of homicides, such as Roth (2009), reveal that the frontier was anything but peaceful. Furthermore, we find that this original violence has cast a long shadow on history and still persists today.

The persistence of violence implies that a relatively short-term and quasiexogenous variation in the institutional environment in which natural resources' discoveries occurred can be associated with large and sustained differences in subsequent institutional and cultural developments. Our results are indeed all the more intriguing because we are dealing with short-lived differences in institutional quality, since all areas in our study finally came under the control of the US government. We control throughout the analysis for state-level fixed effects, which absorb any heterogeneity in today's institutional quality across the US states. Any remaining variation in crime rates must therefore reflect variation in more local institutions or in informal norms that sustain the use of interpersonal violence. The interpretation 
of our results is that where mineral deposits were discovered before the state was in place, violence was a very valuable means of defending private property. Moreover, the shift in norms underlying the use of interpersonal violence was large enough to lock these areas in a cultural-institutional equilibrium characterized by high and persistent violence.

Our results hinge on the assumption of quasi-random variation in the relative timings of state development and mineral discovery at the precise place of discovery, conditional on a set of observable characteristics. We implement several empirical strategies to demonstrate that there is no systematic relationship between mineral discoveries and the political organization of a county. Another potential threat to our identification is that pre-statehood discoveries tend to reflect more recent institutions since, by definition, all pre-statehood discoveries occurred before the US government gained full territorial control at the turn of the 19th century. We therefore control for the precise date of political organization of the county of discovery, and for an exhaustive set of historical and geographic characteristics that are correlated with state development at the local level, such as availability of water ways, agricultural suitability, terrain roughness, distance to the state's capital, population density, and education. We also make sure that our results carry through when we consider only counties that are neighboring one another or only counties that have mineral deposits, as well as when we take into account potential spatial correlation of errors. All these strategies reduce unobserved heterogeneity between counties but leave our results unchanged.

This paper makes contributions to three distinct strands of the literature. The first one is to the literature on the resource curse and on how natural resources shape cultural and institutional development in the long run. ${ }^{2}$ We show that natural resource discoveries lead to persistently higher violence-the homicide resource curse-but only when they occur in the absence of formal institutions.

Our second contribution is to the literature on interpersonal violence. We find that third party enforcement deters violent crime not only in the short-run as reported by Levitt (1997), Kessler and Levitt (1999), and Draca et al. (2011), but also in the longrun. Our results imply that even temporary breakdowns in legal enforcement can have deleterious long-run consequences.

Finally, our results are also related to the literature on cultures of violence. Nisbett and Cohen (1996) and Grosjean (2014) argue that the high prevalence of homicide in the South of the United States originates from the Scots-Irish who settled in the 18th century. The Scots-Irish, it is assumed, were prone to violence because they came from lawless areas and relied on easily stolen resources. Our work provides a justification for this assumption by showing how, indeed, the combination of weak formal institutions and appropriable resources spurs violence and generates a persistent culture of violence.

2. See, among others, Engerman and Sokoloff $(1997,2002)$ and Rajan (2009) for the influence of initial endowment on institutional development. Durante (2009) and Alesina et al. (2013) link trust and gender norms to agricultural conditions and endowments, respectively. 
The remainder of the paper is organized as follows. The conceptual background on the relationship between rule of law and violence is discussed in Section 2. Section 3 introduces mineral discoveries data and describes our empirical strategy. Sections 4 and 5 provide historical and present-day evidence. Section 6 concludes.

\section{Conceptual Background}

\subsection{Main Hypothesis}

Weak third-party enforcement of property rights gives rise to violence, particularly in the presence of valuable resources that can be appropriated. This occurs because interpersonal violence and state enforcement are substitute ways of enforcing or defending property rights. Several models characterize the incentives to engage in violent predatory behavior when the rule of law is absent or weak (Skaperdas 1992; Gonzalez 2012; Bisin and Verdier 2015). Beyond direct expropriation, violence is also be used for preemption (Chassang and Padró i Miquel 2010) or in order create a reputation for being violent (Silverman 2004; Ghosh et al. 2013).

Applying these models' predictions to the context of mineral exploration in the United States, we expect very different degrees of violence as a function of whether formal institutions are in place or not at the time of discovery. If valuable minerals are discovered when the rule of law is absent, as was the case in areas of the frontier that had not yet come under government control, interpersonal violence will be used to defend or enforce property rights or to build a reputation for being violent that will deter attacks. Violence will thus prevail where the state is absent. In contrast, there are no incentives to use interpersonal violence if resources are discovered whereas property rights are backed by the state. The question therefore arises as to what underlies the persistence of interpersonal violence. In other words, is it possible that different initial institutional conditions give rise to different trajectories and steady states of violence?

\subsection{Channels of Transmission}

The first channel of persistence is the quality of institutions. If the absence of the state rewards individuals with a comparative advantage in violence, then these individuals will be able, through predation and intimidation, to secure a larger share of the surplus. A classic case of political capture may then arise when the state eventually arrives. According to Engerman and Sokoloff (1997, 2002) and Rajan (2009), such individuals are able to use their economic power to influence the design of formal institutions in the aim of preserving their rents, with negative long-run consequences for the quality of institutions. The persistence of formal institutions-documented by Acemoglu et al. (2001) and Dell (2010) among others-implies that high levels of interpersonal violence may persist over time.

A second channel of persistence is culture. The economic environment, including the quality of formal institutions, shapes cultural norms, which persist over time. 
Tabellini (2008) and Guiso et al. (2008) study the case of social trust and describe how parental transmission of preferences depends on the spatial pattern of external enforcement. If formal enforcement is weak, parents might transmit low trust in order to protect their children from situations in which they would be taken advantage of. This results in low social trust. The same argument can easily be extended to aggressiveness. If enforcement is weak at one period of time, the returns to interpersonal violence are high and parents will wish their children to internalize the benefits of using violence. Consequently, they will transmit norms that legitimize the use of force. Elias (1994) already underlined the idea that the development of state institutions weeds out violent social norms as agents internalize the social control of violence and even become, in the end, so civilized that they are unable to bite another individual with any meaningful effectiveness. The strong strategic complementarity between violent strategies-one's propensity for violence is increasing in the actual or expected violence of othersimplies that such a culture of violence would be highly persistent. ${ }^{3}$

\subsection{Disentangling Channels of Transmission}

In most models of culture, differences in the initial quality of institutions give rise to different cultural norms that persist over time regardless of subsequent changes in the quality of institutions. However, perhaps a more realistic account is that weak institutions and violent social norms reinforce one another in a coevolutionary process. In theoretical models by Tabellini (2008) and Belloc and Bowles (2013), institutional and cultural persistence are complements. This complementarity gives rise to multiple stable cultural-institutional equilibria. ${ }^{4}$ Bisin and Verdier (2015) show that cultural norms and formal institutions coevolve, and that a temporary and exogenous shocks to the quality of institutions can trigger large differences in long-run institutional and cultural stationary states. Our paper focuses on such a temporary shock to the quality of initial institutions by using quasi-random variation in the presence of state institutions at the time of mineral discoveries. The testable hypothesis is that such a temporary and quasi-exogenous shock to the quality of institutions generated differences in interpersonal violence that have persisted up to this day.

Empirically, culture is generally identified as the residual effect of an historical shock or event, once the contemporaneous influence of formal institutions has been taken into account. Authors generally attempt to control for the quality of formal institutions by focusing on regional differences within a given country (see Guiso et al. 2008 among others) or by including country-level fixed effects in multicountry studies (see, e.g., Nunn and Wantchekon 2011; Alesina et al. 2013), based on the

3. Young (1998) theoretically shows that norms that are mutual best responses are evolutionary stable.

4. Empirically, Grosjean (2014) and Restrepo (2015) show that the interaction between violent cultural norms and formal institutions allows for two possible stable equilibria. Violent norms are, for example, more beneficial when formal institutions are weak and are therefore reinforced. In turn, individuals with violent cultural norms tend to favor taking justice into their own hands and are less supportive of the development of strong formal institutions. 
assumption that formal institutions vary at the country level. In this paper, we not only focus on a single country, the United States, but also include state-level fixed effects, which absorb any unobserved potential heterogeneity in the quality of institutions across the US states. Therefore, in the traditional understanding of the empirical literature on culture, any remaining variation associated with the historical shock that we study in this paper could be interpreted as evidence of cross-county differences in social norms that sustain the use of interpersonal violence.

However, the recent literature on the coevolution of culture and institutions highlights that the traditional empirical identification of culture and institution as separate channels of persistence is impracticable. Differences in social norms imply that even identical formal institutions may be enforced differently in a way that further reinforces social norms. For example, in areas where social norms are more encouraging and tolerant of violence, popular juries would be more lenient toward violent offenders, and the anticipation of lighter sentences may encourage more violence. This interpretation is consistent with the theoretical literature on the joint evolution of institutions and culture, which views institutional and cultural persistence as two intrinsically linked and complementary processes.

\section{Data and Empirical Strategy}

This section presents the data and the empirical strategy we adopt.

\subsection{Data on Natural Resources and State Development}

The MRDS describes the location of mineral resources throughout the world. For the United States, the dataset contains slightly more than 17,500 observations on mineral deposits for which information on the precise location and on the year of discovery is available. The mineral resource discoveries span the years from 1640 to $1998 .^{5}$

The Atlas of Historical County Boundaries provides information about the creation and all subsequent changes in the administrative status, size, shape, location, and dates of boundary changes of every county in the United States. ${ }^{6}$ This information is also available for administrative areas such as colonies and territories. We construct as many yearly maps of the administrative boundaries of counties and states in the contiguous United States as there are distinct discovery years in the MRDS. We then project each mineral deposit on the map of administrative boundaries that corresponds to its year of discovery, and we record the administrative status of the place of discovery at the point in time of discovery. The rule of thumb we use is to consider that an area is

5. For the sake of clarity, the discussion of the potential caveats due to the MRDS containing observations for which the discovery date is missing is presented in a dedicated section in the Online Appendix.

6. The county is the relevant unit to study state development. A large geographic area could be declared a state without state representation over the whole area (i.e., it could still include unincorporated land or unorganized territory). The area would then be gradually incorporated into counties and, once all areas are organized into counties, the full state could be considered to be incorporated. 
politically organized at a given point in time if it belongs to a county within a state or to a colony. In contrast, we consider as not politically organized areas such as territories or de facto unorganized land. ${ }^{7}$ This allows us to categorize each mineral discovery as a pre-statehood or post-statehood discovery depending on whether it occurred before or after political organization.

Then, for each US county today, we count all of the mineral discoveries that have ever occurred within its present-day boundaries, as well as whether each discovery was pre- or post-statehood, according to our classification. Any issue arising from redistricting and county boundary changes is automatically taken into account since we only consider the status of the place of discovery at the time of discovery.

Our independent variables of interest are the number of pre- or post-statehood mineral discoveries within the boundaries of a given county. All in all, out of the 3,108 counties that form the contiguous United States today, 849 (27.3\%) have had minerals discovered within their boundaries. About a quarter of them (217) experienced pre-statehood discoveries. For obvious geological reasons, places that experienced prestatehood discoveries are also likely to experience further discoveries. Indeed, 201 out of the 217 counties that experienced pre-statehood discoveries experienced further discoveries after the area was incorporated into statehood.

Because each county and US state incorporated territory gradually, and because discoveries occurred at different times, there is substantial within-state variation in the number of counties with pre- or post-statehood discoveries. These differences are illustrated in Figure 1 that highlights US counties with mineral resources and shows how pre-statehood discoveries varied across the counties. The largest shares of prestatehood discoveries can be found in the West, where mineral exploration and state construction occurred at the same time. Yet, thanks to the historical span of our data, there is variation in the share of pre-statehood discoveries across the whole territory.

Figure 2 plots together the distribution of mineral resource discoveries over time and the territorial expansion of the US government. The solid line represents the share of the area of the present-day contiguous United States that was integrated either into a colony or a state at each date between 1,750 and today. The dashed line represents the number of mineral discoveries occurring each year. Both series sharply accelerated around 1,825. However, although the administrative organization of the territory was achieved by the beginning of the 20th century, substantial mineral discoveries continued until the end of the Second World War. The distributions displayed by Figure 2 evoke the basic source of variation we rely on: some discoveries occurred before the land was politically organized, others after. To display our source of identification more clearly, Figure 2 distinguishes between mineral discoveries that occurred prior to or after political organization. The area under the second, inner dashed line represents the share of pre-statehood discoveries. Because the government gradually expanded over time, pre-statehood discoveries tend to occur earlier (in fact, no pre-statehood discovery

7. Territories refer to the territorial status between the transfer of sovereignty to the Union and the actual establishment of formal US institutions. Even though territories were technically under the jurisdiction of the United States, in practice law enforcement was minimal. 


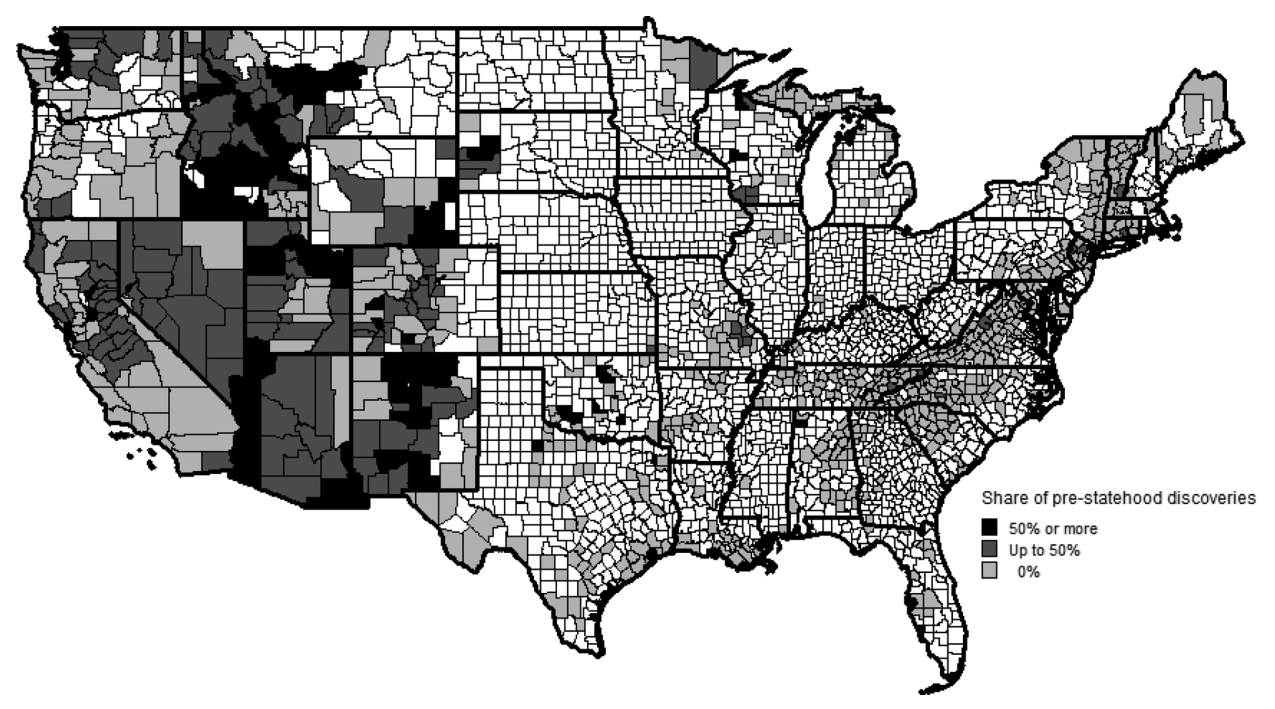

FIGURE 1. US counties' mining history. Sources: Atlas of Historical County Boundaries and Mineral Resources Data System. White counties are counties that never experienced mineral resource discoveries. Light-gray counties experienced mineral resource discoveries only once land was administratively organized. Medium-gray and black counties experienced some mineral resource discoveries before land was administratively organized.

can occur after full state incorporation of the United States, i.e., after the solid line reaches 1). However, there is still substantial variation over time, with pre-statehood discoveries spanning almost a century.

It should be noted here that although we are able to find records of mineral discoveries prior to administrative organization of the land, no other outcome or county characteristics is systematically available for the time period that preceded political organization. For example, no Census data was ever collected before an area was politically organized as an administered entity of the United States. Therefore, even in historical regressions, we cannot observe any outcome at the time of a pre-statehood discovery.

\subsection{Data on Violence}

3.2.1. Historical Crime Data. Data on historical crime are from the Historical Violence Database of the Criminal Justice Research Center at Ohio State University. This database is a collection of datasets that have been collected by historians using different sources such as coroner's reports, newspaper accounts, and homicide detective reports. ${ }^{8}$ From this database, we assemble an unbalanced panel of 63 counties across

8. For example, Mullen (2005) gathered data on homicide in San Francisco since 1849, using newspaper reports before the Great Earthquake of 1906 and homicide detective reports for the years after. 


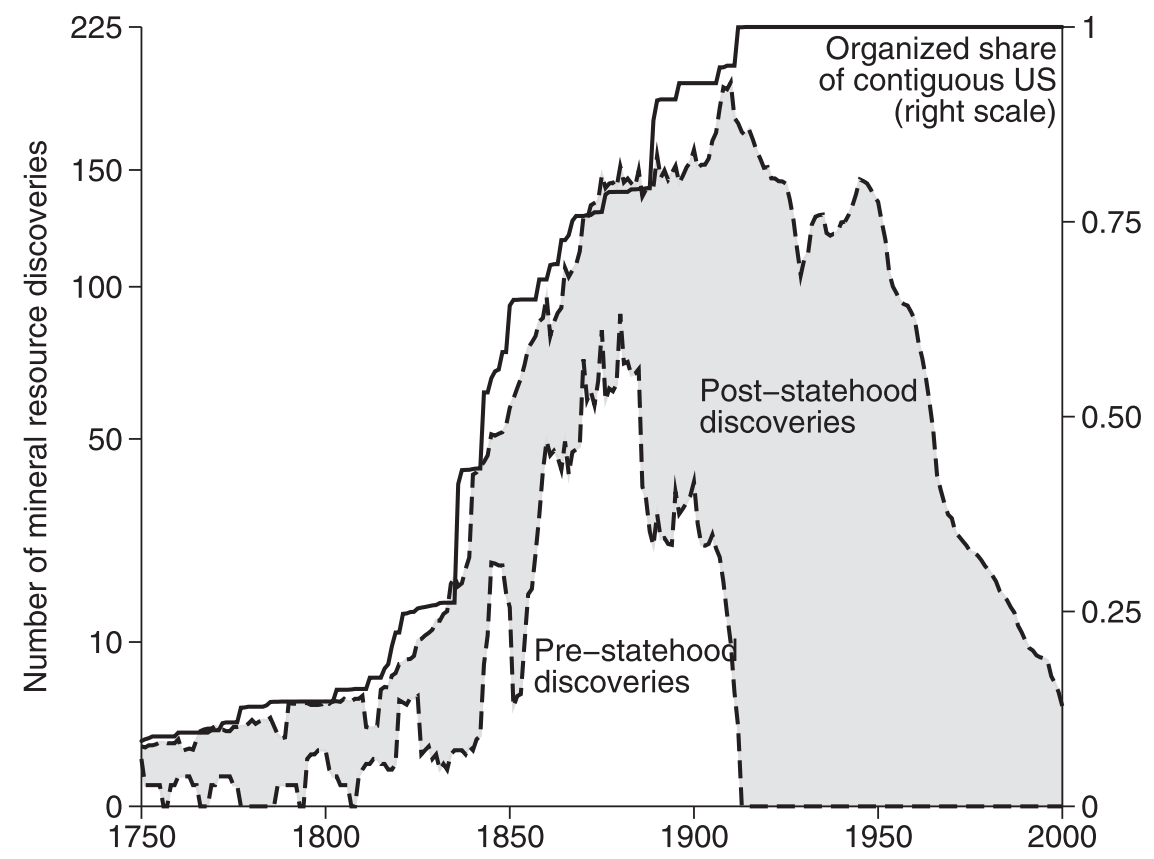

FIGURE 2. Political organization and mineral discoveries over time. Sources: Atlas of Historical County Boundaries and Mineral Resources Data System. The cumulative distribution of counties' political organization is built based on present-day counties' boundaries but takes redistricting into account as explained in Section 3.1. The distributions of mineral discoveries have been smoothed for graphical considerations. The top line has been smoothed using a 20 -year window. The bottom line, that is, the one that distinguishes between discoveries made before or after the land was politically organized, has been smoothed using a 5-year forward-looking window.

10 states from 1790 to 1900 , yielding to 3,588 county-year observations. ${ }^{9,}{ }^{10}$ Historical crime data are matched to every wave of the US Census from 1790 to 1900-available from Haines and Inter-University Consortium for Political \& Social Research (2010)_ to obtain homicide rates per 1,000 people. ${ }^{11}$ Because the Census is only taken every 10 years whereas the crime data are yearly, we linearly extrapolate data on population at the county level.

3.2.2. Present Day Data on Violence. Data on present day violence are from the Uniform Crime Reporting (UCR) Program published by the United States Department

9. See Table A.1 in the Online Appendix for the number of county-year observations available in each state.

10. Some historical samples were selected to study specific issues, such as inter-racial violence in the case of McKanna (1997). However, none of these issues is directly related to the development of state institutions at the time of mineral discoveries, which we study in this paper.

11. Homicide is measured per 1,000 people instead of the more standard measure per 100,000 people because historical homicide rates are much higher than present-day homicide rates. 
of Justice and the Federal Bureau of Investigation. UCR provides information on 43 types of offenses and the monthly count of arrests for each offense from more than 17,000 reporting agencies. Because the number of reporting agencies has been increasing over the years, we use more recent and more reliable data. ${ }^{12}$ Using the 2000 Census, we construct our contemporary dependent variable of interest as the county-level rate of violent crimes per 100,000 people in 2000. We consider as violent crimes offenses labeled as "murders", "aggravated assaults", and "other assaults".

\subsection{Empirical Strategy}

Our estimation strategy involves two steps. First, we study systematic evidence on the short-term historical relationship between mineral discoveries and violence at the county level. Second, we investigate the enduring relationship between counties' mining and political history and violence today.

3.3.1. Historical Analysis. We match historical data on violence with information about yearly mining discoveries extracted from the MRDS and estimate the following expression:

$$
\begin{aligned}
\text { Homicide }_{i t}= & \beta_{0}+\beta_{1} \text { Discovery }_{i t}+\beta_{2} \text { Discovery }_{i t} \times \text { Pre-statehood }_{i} \\
& +\delta_{i}+\delta_{t}+\varepsilon_{i t},
\end{aligned}
$$

where Homicide $_{i t}$ denotes the rate of homicides per 1,000 people in county $i$ at year $t$, Discovery is $_{i t}$ alternatively a dummy equal to 1 if county $i$ experiences a mineral discovery at year $t$ or the number of discoveries in county $i$ at year $t$, and Pre-statehood is a dummy equal to 1 for counties that ever experienced a pre-statehood discovery, according to our classification detailed in Section 3.1. The panel-structure of our historical data enables us to introduce year fixed effects $\left(\delta_{t}\right)$ and county fixed effects $\left(\delta_{i}\right)$ in order to account for common time shocks and time-invariant county characteristics, respectively. $\varepsilon_{i t}$ is the error term. We estimate expression (1) using ordinary least squares and cluster errors at the county level. $\beta_{1}$ should be interpreted as the average relation between discoveries and homicides, whereas $\beta_{2}$ signals whether the former relationship is conditioned by the past mining and political history of the counties.

3.3.2. Present-Day Evidence. To examine the relationship between violence today and counties' mining and political history, we estimate the following specification:

$$
\begin{aligned}
\text { Violence }_{i}= & \beta_{0}+\beta_{1} \text { Post-statehood discoveries }_{i} \\
& +\beta_{2} \text { Pre-statehood discoveries } \\
i & +\mathrm{X}_{i}^{\prime} \beta_{3}+\delta_{s(i)}+\varepsilon_{i},
\end{aligned}
$$

12. As signaled by the data provider itself in its codebook, the quality of UCR data is heterogeneous as reporting methods can vary across agencies. We include UCR's county-level coverage indicator as a right-hand side variable in all estimations that use these data as an attempt to control for variation in data quality across counties. Our results are unaffected by the inclusion of this control. 
where Violence $_{i}$ is the violent crime rate per 100,000 people in county $i$ in 2000.

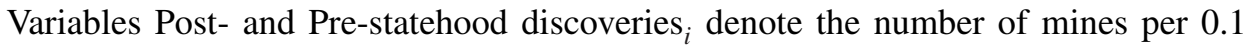
square mile that were discovered in county $i$ after or before formal institutions were established. Note that scaling these variables by a county's size allows us to ensure their comparability across counties of various sizes. $X_{\mathrm{i}}$ is a vector of county-level covariates that we describe as we introduce them. $\delta_{s(i)}$ is a vector of state fixed effects that enable us to account for potential regional differences in crimes rate and variation in institutional quality across states, and $\varepsilon_{i}$ is the error term. We estimate expression (2) using ordinary least squares and cluster errors at the state level. The coefficients can be interpreted as follows: $\beta_{1}$ captures the relationship between discoveries that occurred after the land was already politically organized and today's violent crimes; $\beta_{2}$ captures the relationship between discoveries that occurred when the land was not yet administratively organized and today's violent crimes.

3.3.3. Independence of State Development and Mineral Discoveries. We use variation in the respective timings of mineral discovery and state development as the source of identification to estimate the effect of state development on violence. The underlying identification assumption is that, conditional on a set of observable characteristics, there is quasi-random variation in the timing of state development around the time of mineral discoveries. We discuss two particular facts in American economic history that support this hypothesis, and we implement two empirical tests that support each of these facts.

First, Davis et al. (1972) argues that the US government territorial expansion was largely driven by population pressure and external geopolitical forces, which are hopefully not correlated with the location of mineral resources. Table 1 helps illustrate this claim. We analyze the relative explanatory power of different determinants of counties' political organization dates. The table displays the estimates and the adjusted $R$-squared from regressions of the date at which the territory of a county was first administratively organized into a colony or state on various explanatory variables. ${ }^{13}$ As shown by column (1), counties with mineral resources were organized sooner than others. However, mineral resources endowment only explains $0.7 \%$ of the variation in political organization dates. By contrast, geographical characteristics such as latitude and longitude, agricultural suitability, elevation, roughness of terrain, or local rivers' length each explain between $7 \%$ and $49 \%$ of the variation in organization dates as shown by adjusted $R$-squared of columns (2-5). Simultaneously including all of these variables other than mineral discoveries as explanatory variables pushes the adjusted $R$-squared up to $55 \%$. This sharply contrasts with the low explanatory power of mineral resources endowments and advocates against the presence of minerals being an important driver of land's political organization.

Because these geographic characteristics explain a substantial part of the variation across dates of political organization, we include them in the set of controls in $X_{i}$ in

13. See Table A.8 in the Online Appendix for sources and definitions of explanatory variables. 
TABLE 1. Determinants of county-level political organization dates.

Dependent variable: date at which a county's land was first politically organized (colony or state)

(1)

(2)

(3)

(4)

(5)

(6)

\begin{tabular}{|c|c|c|c|c|c|c|}
\hline Mineral discoveries & $\begin{array}{c}-25.25^{* * *} \\
(5.48)\end{array}$ & & & & & \\
\hline Longitude & & $\begin{array}{c}-3.77^{* * * *} \\
(0.09)\end{array}$ & & & & $\begin{array}{c}-3.44^{* * *} \\
(0.09)\end{array}$ \\
\hline Latitude & & $\begin{array}{c}-0.51^{* * *} \\
(0.15)\end{array}$ & & & & $\begin{array}{c}-1.41^{* * *} \\
(0.17)\end{array}$ \\
\hline Mean agricultural suitability & & & $\begin{array}{l}53.69^{* * *} \\
(3.02)\end{array}$ & & & $\begin{array}{l}47.09^{* * *} \\
(2.56)\end{array}$ \\
\hline Mean elevation & & & & $\begin{array}{l}0.05^{* * *} \\
(0.00)\end{array}$ & & $\begin{array}{l}0.01^{* * *} \\
(0.00)\end{array}$ \\
\hline Standard deviation of elevation & & & & $\begin{array}{c}-0.40^{* * *} \\
(0.04)\end{array}$ & & $\begin{array}{c}-0.15^{* * *} \\
(0.02)\end{array}$ \\
\hline Total rivers' length & & & & & $\begin{array}{l}0.04^{* * *} \\
(0.00)\end{array}$ & $\begin{array}{c}-0.00^{* *} \\
(0.00)\end{array}$ \\
\hline Observations & 3,108 & 3,108 & 3,108 & 3,108 & 3,108 & 3,108 \\
\hline Adjusted $R$-squared & 0.007 & 0.487 & 0.087 & 0.177 & 0.068 & 0.551 \\
\hline
\end{tabular}

Notes: OLS regressions. Each column presents the estimates from a separate regression. The unit of observation is a county. White heteroskedastic standard errors are given in parentheses. Mineral discoveries are the number of mineral discoveries per 0.1 square mile. All regressions include a constant term. See Table A.8 in the Online Appendix for sources and definitions of other variables. ${ }^{* *} p<0.01,{ }^{* *} p<0.05,{ }^{*} p<0.1$.

equation (2). The date of a county's political organization may also influence crime directly, because the quality of formal institutions may depend on how long formal institutions have been in place in a given county. In order to account for such potential differences in the quality of institutions across counties, we also include the date of political organization of the county in the vector of covariates. Last, we also include in $\mathrm{X}_{\mathrm{i}}$ a set of historical socioeconomic characteristics that could be correlated with the date of political organization, the quality of formal institutions and long-run trends in crime, and which reflect population density, education, economic inequality, poverty, and ethnic fractionalization.

The second fact in American mining history that argues in favor of the independence of discoveries from the precise date of political organization is that mineral exploration in the United States occurred in a rather unorganized "rush". According to Wright (1990), the most distinctive feature of the American mining economy was the intensity of exploration and exploitation. This was due to a particularly rewarding incentive system, in which, as opposed to most other countries in the world, mineral rights were included in the bundle of land rights (David and Wright 1995). Exploration was to a large extent a private enterprise, in which Clay and Wright (2011) describe as an open and saturated market. As an illustration, in around 1850, miners in California earned on average less in relative terms than day laborers in other parts of the United States, an indication that open entry gave way to a dissipation of rents (Clay and Jones 2008). Taken together, such a private and massive search in a market with open entry-the 


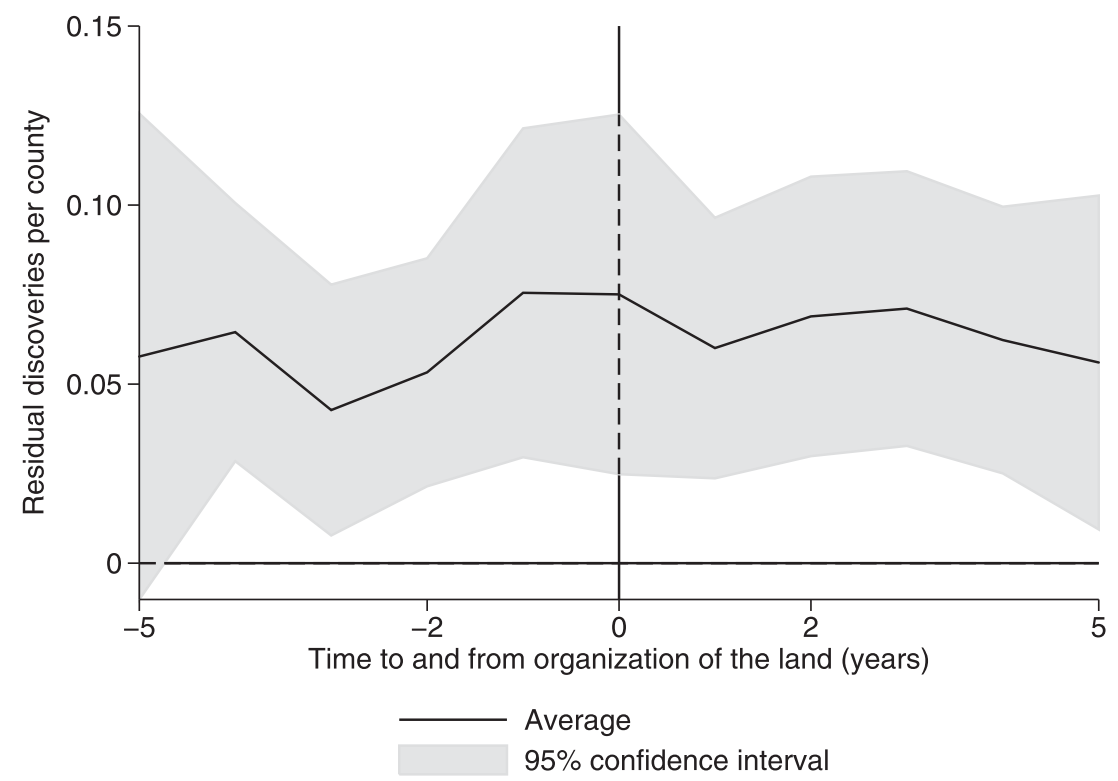

FIGURE 3. Residual discoveries around political organization of the place of discovery. Sources: Authors' calculations from the Atlas of Historical County Boundaries and the Mineral Resources Data System. Residual discoveries per county is the residual from a regression of yearly mineral discoveries that took place within a county's boundaries on a set of year and county fixed effects.

mineral rush-suggests that specific mineral discoveries were largely independent from the political status of the place of discovery at the time of discovery.

We empirically check for this independence by computing the residuals from a regression of yearly local discoveries on a set of county and year fixed effects. County fixed effects wash out the local mineral potential, whereas year fixed effects take into account population pressure, variation in the price of minerals, and the evolution of any relevant technology. We then average these residuals across time to and from the date at which a county's land was politically organized. Figure 3 plots such residuals within a 10-year window around the political organization of the county. Since, as depicted by Figure 2, mineral discoveries and county political organization tended to occur at the same time, residuals are positive around the date of political organization. However, the pattern of the residuals is not different before and after the date of political organization. This confirms that there is no particular association between administrative status and the number of mineral discoveries in a given county around the date of political organization.

3.3.4. Other Threats to Identification. Our identification method relies on a comparison across counties within the same state. A threat to our identification strategy could consist of the unobserved heterogeneity in mining and political histories across counties. First, a county may have been affected by the mining history of its 
immediate neighbors rather than more distant counties even within the same state. This would imply that the relevant comparison group may not be any county in the same state but only neighboring ones and that the error term in equation (2) is spatially correlated and not independently and identically distributed within a state. A second and related concern is that mineral resources' endowment is not evenly distributed across space: minerals tend to be clustered geographically. Finally, counties located near state boundaries may share some characteristics with counties on the other side of the state border, which are not captured by state fixed effects. We present numerous strategies to tackle these different threats in Section 5.2.

\section{Historical Evidence}

In this section, we present evidence that the historical relationship between mineral discoveries and interpersonal violence depends on the political circumstances of mineral discoveries.

\subsection{Descriptive Statistics and Main Results}

4.1.1. Descriptive Statistics. Our sample is a nonbalanced panel of 63 counties across 10 states from 1790 to 1900. Fourteen of these counties experienced mineral discoveries, and some discoveries occurred before administrative organization in five of the counties. ${ }^{14}$ For these five counties there is an average of 0.26 discoveries a year with a maximum of five discoveries. For counties that did not experience prestatehood discoveries, there is on average 0.08 discoveries a year with a maximum of 6 discoveries.

In counties with pre-statehood discoveries, the average yearly homicide rate reaches 0.24 per 1,000 inhabitants. It is larger than the corresponding figure in counties without any mineral discoveries (0.07). It is also higher compared to counties that only experienced mineral discoveries after political organization $(0.10) .{ }^{15}$ This simple crosssection evidence illustrates the fact that even back in the past, counties that experienced mineral discoveries prior to administrative organization were more violent than other counties.

Within the sample of counties endowed with mineral resources, the average homicide rate during the years where mineral discoveries occurred is 0.34 per 1,000 inhabitants. It is four times larger than the average homicide rate during years without

14. The five counties that experience pre-statehood discoveries are Augusta (Virginia), Calaveras (California), Gila (Arizona), Sacramento (California), and Tuolumne (California). It represents $6.4 \%$ of county-year observations.

15. Formal tests of the differences between 0.24 and 0.10 or 0.07 suggest that they are statistically significant, with $t$-statistics equal to 4.7 and 8.4 , respectively. 
TABLE 2. Historical evidence on mineral discoveries and homicide: 1790-1900 in an unbalanced panel of counties.

Dependent variable: yearly rate of homicide per 1,000 inhabitants
(1)
(2)
(3)

(4)

(5)

(6)

\begin{tabular}{lccccccc}
\hline Discovery & $0.26^{* *}$ & -0.03 & -0.14 & & -0.07 & \\
& $(0.10)$ & $(0.08)$ & $(0.10)$ & & $(0.08)$ & \\
Discovery $\times$ pre-statehood & & & $0.22^{*}$ & & $0.31^{*}$ & \\
& & & $(0.12)$ & & $(0.19)$ & \\
Number of discoveries & & & & $-0.09^{* * *}$ & & -0.04 \\
& & & & $(0.03)$ & & $(0.04)$ \\
Number of discoveries $\times$ pre-statehood & & & & $0.14^{* * *}$ & & $0.15^{* *}$ \\
& & & & $(0.03)$ & & $(0.07)$ \\
\hline County fixed effects & & Yes & Yes & Yes & Yes & Yes \\
Year fixed effects & & Yes & Yes & Yes & Yes & Yes \\
Gold only & & & & & Yes & Yes \\
\hline Observations & \multirow{2}{*}{3,588} & 3,588 & 3,588 & 3,588 & 3,588 & 3,588 \\
$R$-squared & 0.02 & 0.30 & 0.30 & 0.31 & 0.31 & 0.30 \\
\hline
\end{tabular}

Notes: OLS regressions. Each column presents estimates from a separate regression. The unit of observation is a county year. White heteroskedastic standard errors adjusted for clustering at the county level are given in parentheses. Discovery is a dummy equal to 1 if county $i$ experiments a mineral discovery in a given year. Prestatehood is a dummy variable equal to 1 for counties that ever experienced a pre-statehood discovery. Gold is the only mineral resource taken into account to construct the variables used in columns (5) and (6). All regressions include a constant term. Online Appendix Table A.1 presents sources used to construct the sample. ${ }^{* * *} p<0.01$, ${ }^{* *} p<0.05,{ }^{*} p<0.1$.

discoveries (0.09). ${ }^{16}$ This depicts the within-county time-variation we exploit to estimate equation (1).

4.1.2. Main Results. Estimates of equation (1) are presented in Table $2 .{ }^{17}$ In the first column, without year and county fixed effects, the coefficient associated with the discovery of mineral resources is positive and statistically significant. However, this conflates potential differences between mining and nonmining areas that are fixed over time, potential trends in violence that are correlated with the timing of mineral exploitation, as well as the contemporaneous effect of mineral discoveries on violence. To isolate the third channel, we include year and county fixed effects in column (2) and thereafter. County fixed effects absorb the effect of any unobservable but timeinvariant differences between mining and nonmining areas that could influence the level of violence. Year fixed effects deal with any potential secular trend in violence that could be correlated with mining activity. With the inclusion of time and year fixed

16. A formal test of the difference between 0.34 and 0.09 provides a $t$-statistic equal to 7.4 and confirms that the difference is statistically significant.

17. Note that counties that never experienced mineral resource discoveries do not help us directly to estimate the coefficients of interest of equation (1). However, they do help us to estimate time fixed effects capturing common time shocks that might influence violence during specific years. 
effects, the coefficient associated with the discovery of mineral resources is no longer significant. This indicates that mineral discoveries per se are not conducive to violence. However, when we take into account counties' political histories, the story is different. In counties that experienced some discoveries prior to state development, every new discovery has a positive and statistically significant effect on violence. In column (3), the coefficient associated with the interaction term between the discovery of mineral resources and the dummy variable that indicates whether there were discoveries before political organization is positive and statistically significant. The magnitude of the effect of prestate discoveries is substantial. According to the estimates presented in column (3) of Table 2, a mineral discovery in a pre-statehood county is associated with a spike in the rate of violent crime by almost $100 \%$.

In columns (4-6), we document that this finding holds when considering the intensive rather than the extensive margin, that is, using the yearly number of mineral discoveries instead of a dummy, or when we impose restrictions on minerals, for example, when we consider gold discoveries only. Note that the coefficients associated with mineral discoveries and with the interaction term are both statistically significant in column (4). However, the coefficient associated with the interaction term is larger in magnitude than the coefficient associated with discoveries and still positive. In columns (5) and (6), we observe a slight increase in the magnitude of the coefficient of the interaction term as we focus on gold, an ore that is more valuable. This observation matches the intuition that the relationship between mineral discoveries and violence should be stronger for more valuable resources.

\subsection{Robustness}

4.2.1. Spatial Correlation. Counties that are geographically close to one another may be influenced by common characteristics that could affect both their mining and political history, as well as prevailing violence. For example, minerals tend to be geographically clustered. Governmental territorial expansion also had a spatial dimension, with places near the frontier more likely to become politically organized and also benefit from some third party enforcement compared with places further away from the frontier. We use the estimation method pioneered by Conley (1999, 2008) and further developed by Hsiang (2010) to deal with the resulting potential spatial correlation in the error term of expression (1). In columns (1) and (2) of Table A.2, presented in the Online Appendix, standard errors are adjusted for spatial correlation within a 100 - and 500-km radius. Standard errors appear to be very similar to those displayed in column (3) of Table 2.

4.2.2. Heterogeneity Arising from Trends. Our identification strategy relies on within county variation and on the assumption that all the counties in our sample would have experienced similar trends in the absence of additional discoveries. We relax this assumption and add county-specific time trends in column (3) of Table A.2 to ensure that our result is not driven by the heterogeneity arising from trends in homicide rates 
that may be correlated with mineral discoveries within a county. The magnitude of the point estimate of the interaction term is unaffected.

4.2.3. Outliers. Columns (4-6) of Table A.2 display two approaches that allow us to ensure that our estimates of interest are not driven by counties with outlying rates of violence. Our estimate is not affected by a log-transformation of the dependent variable, nor by excluding two- and three-sigma outliers.

To conclude, we find that mineral discoveries were associated with contemporaneous spikes in violence, but only in counties where some minerals had been discovered before state development. We now study whether violence has endured in these areas, even though the economy has long shifted away from the exploitation of minerals.

\section{Present-Day Evidence}

In this section, we present evidence that violence is still, today, related to counties' mining and political history.

\subsection{Results}

The first column of Table 3 displays the estimated coefficients obtained when estimating equation (2) on the population of the 3,108 counties in the contiguous United States without the vector of covariates. The coefficients associated with pre- and post-statehood discoveries are both statistically significant. However, the coefficient associated with pre-statehood discoveries is more than five times larger in magnitude and positive, whereas the coefficient associated with post-statehood discoveries is negative. This suggests that although counties that only experienced mineral discoveries after political organization tend to experience less violence than nonmining counties, areas where mineral discoveries occurred before political organization experience, today, more violent crime than either type of counties. As we will see in the rest of this section, only the positive effect of pre-statehood discoveries on violence remains robust to additional tests.

Columns (2-4) of Table 3 present the evolution of coefficients of interest when introducing different sets of county-level covariates in equation (2). ${ }^{18}$ A county's political history may have an influence on present-day violence not only through its interaction with mining history but also directly, through an institutional quality channel. To account for this, we control for the date of political organization, as well as for the covariates that were shown to influence the date at which political organization occurred, according to the analysis performed in Table 1. We also include

18. Summary statistics and estimates of covariates are displayed in Table A.3, presented in the Online Appendix. 
TABLE 3. Political and mining history and present-day violent crime.

Dependent variable: rate of violent crime per 100,000 inhabitants in 2000

\begin{tabular}{|c|c|c|c|c|c|}
\hline Pre-statehood discoveries & $\begin{array}{l}-79.63^{* * *} \\
(28.37) \\
423.06^{* * *} \\
(79.81)\end{array}$ & $\begin{array}{l}-56.37 \\
(35.11) \\
512.80^{* * *} \\
(91.74)\end{array}$ & $\begin{array}{l}-8.77 \\
(25.87) \\
443.65^{* * *} \\
(93.03)\end{array}$ & $\begin{array}{l}-43.33 \\
(26.07) \\
294.67^{* * *} \\
(108.79)\end{array}$ & $\begin{array}{l}-11.71 \\
(28.71) \\
357.10^{* * *} \\
(90.17)\end{array}$ \\
\hline $\begin{array}{l}\text { State fixed effects } \\
\text { Geographic controls } \\
\text { Contemporary controls } \\
\text { Historical controls }\end{array}$ & Yes & $\begin{array}{l}\text { Yes } \\
\text { Yes }\end{array}$ & $\begin{array}{l}\text { Yes } \\
\text { Yes }\end{array}$ & Yes & $\begin{array}{l}\text { Yes } \\
\text { Yes } \\
\text { Yes } \\
\text { Yes }\end{array}$ \\
\hline $\begin{array}{l}\text { Observations } \\
R \text {-squared }\end{array}$ & $\begin{array}{c}3,108 \\
0.46\end{array}$ & $\begin{array}{c}3,108 \\
0.48\end{array}$ & $\begin{array}{c}3,054 \\
0.53\end{array}$ & $\begin{array}{c}2,484 \\
0.53\end{array}$ & $\begin{array}{c}2,460 \\
0.56\end{array}$ \\
\hline
\end{tabular}

Notes: OLS regressions. Each column presents the estimates from a separate regression. The unit of observation is a county. White heteroskedastic standard errors adjusted for clustering at the state level in parentheses. Violent crimes include murders, aggravated assaults, and other assaults. Pre- and Post-statehood discoveries are the numbers of mineral discoveries per 0.1 square mile that have been discovered before and after political organization, respectively. All regressions include a constant term and UCR's county-level coverage indicator. Geographic controls: total land area, mean and standard deviation of elevation, agricultural suitability, total length of rivers, a dummy indicating the presence of oil or gas resources, distance to the state's capital, the date at which the county's land was first politically organized, latitude, and longitude. Contemporary controls are measured in 2000: share of population with high school degree, Gini coefficient, population density, per capita income, share of blacks, and ethnic fractionalization. Historical controls: male literacy rate in 1900, population density, share of urban population, share of women, share of non-Whites, per capita farming output and per capita manufacturing output in 1880. Summary statistics and covariates' estimates are presented in Online Appendix Table A.3. See Table A.8 in the Online Appendix for sources and definitions of covariates. ${ }^{* *} p<0.01,{ }^{* *} p<0.05,{ }^{*} p<0.1$.

other county characteristics that are fixed over time and that could be correlated with mining and political history and violence today. These include total land area (to wash out size effects), distance to the state's capital (to take remoteness into account), and a dummy indicating the presence of oil or gas resources (to account for other geological resources). Including these covariates increases the magnitude of the estimated coefficient of pre-statehood mineral discoveries, whereas it decreases the magnitude and the statistical significance of the coefficient on post-statehood discoveries.

The second set of covariates consists of socioeconomic variables measured in 2000 that might influence crime, such as education (proxied by the share of population with a high school degree), inequality (measured by the Gini coefficient), population density, per capita income, black share of the population, and ethnic fractionalization. Introducing these variables leaves the statistical significance and the magnitude of prestatehood discoveries unchanged compared to column (1) but reduces the magnitude of the coefficient of post-statehood discoveries, which is no longer statistically significant. Arguably, some of these present-day county characteristics may have been influenced by a county's mining history and including them in the regression may bias coefficients on the variables capturing mining history. However, it is reassuring to observe that the magnitude of the coefficient on pre-statehood discoveries is hardly affected by the 
inclusion of these controls, whereas the overall fit of the regression improves, with the $R$-squared increasing from 0.46 to 0.53 .

Third, we check that our results are robust to controlling for historical covariates that aim to capture socioeconomic conditions in the distant past. This set includes: male literacy rate in 1900, population density, share of urban population, shares of women and non-Whites, per capita farming output and per capita manufacturing output in 1880. The choice of 1880 and 1900 as measurement dates is the result of a compromise between data availability and our wish to get as close as possible to the moment where minerals were discovered and the land was organized. As a result, the sample size is smaller. ${ }^{19}$ However, introducing these variables preserves our main result: mineral discoveries that occurred before political organization are associated with more violent crime today, whereas this is not the case for mineral resources discovered later in a county's history.

Finally, we simultaneously include the three sets of covariates as shown by column (5) of Table 3. The coefficient associated with pre-statehood mineral discoveries is still negative, statistically significant, and of the same order of magnitude. Meanwhile, minerals discovered after state institutions were in place have no lasting influence on violence.

5.1.1. Potential Omitted Variables. The stability of the coefficient of interest when simultaneously including our three sets of different covariates is reassuring concerning potential omitted variable bias. In order to apply the general estimator proposed by Oster (2015), we compare the estimate of pre-statehood discoveries from the fifth column of Table 3 with the one obtained when using the first column's specification and restricting the sample to counties used in fifth column. We find that the influence of unobservable variables would need to be 1.13 times more important than that of all the already included observable variables to totally suppress the effect of pre-statehood discoveries. $^{20}$

5.1.2. Magnitude. The magnitude of the enduring effect of pre-statehood discoveries is substantial. According to the estimates presented in the last column of Table 3, a one standard deviation change in pre-statehood mineral discoveries is associated with an

19. The extent of selection into this sample can be explored by investigating how different observable characteristics affect the probability of a county falling into this sample. It turns out that the $R$-squared of a linear probability model whose dependent variable is equal to one for counties included in the reduced sample and whose right-hand side variable is mineral endowment equals 0.0004 . In contrast, using the vector of geographic covariates as explanatory variables produced a $R$-squared that reaches 0.20 . This finding suggests than our variables of interest are not key determinants of sample selection and that further taking into account geographic features is important.

20. Note that 1.13 exceeds 1 , the critical value recommended by Oster (2015). We follow the recommendation by Oster (2015) and assume that the maximum achievable $R$-squared exceeds by $30 \%$ the one obtained when including all observable covariates. With the most conservative hypothesis, that is, assuming that the maximum achievable $R$-squared is 1 , we still find that the influence of unobservable variables would need to be 1.07 times larger than the influence of all included observable variables to make the effect of our variable of interest go away. 
increase in the rate of violent crime that amounts to around $4 \%$ of the standard deviation of violent crime rates. This is very close to the effect of more traditional determinants of violence such as education and income. Summary statistics and covariates' estimates, presented in Online Appendix Table A.3, indicate that one standard deviation change in the high school graduation rate or in per capita income is each associated with $5 \%$ changes in the standard deviation of violent crime rates.

5.1.3. Alternative Results. We have so far included all types of minerals in empirical specifications. Table A.4 in the Online Appendix displays estimates that mirror those in columns (1) and (5) of Table 3 for different kinds of minerals. We first restrict ourselves to metallic minerals. Our estimates are unchanged. We then focus on silver and gold. While the main message conveyed by these estimates remains unchanged, we observe a slight increase in the magnitude of the coefficient of pre-statehood discoveries as we focus on more valuable ores, which is consistent with our intuition.

Our story relies exclusively on the persistence of interpersonal violence. As a placebo exercise, we check whether pre-statehood discoveries translate into all forms of criminality. We achieve this by replacing our dependent variable with different crimes rates: property crimes, drug crimes, and all other crimes. As shown by the estimates displayed in Table A.5, pre-statehood discoveries hardly have any effect on these different measures of crime rates, giving a hand to our story of persistence of interpersonal violence.

\subsection{Threats to Identification}

As already mentioned, our identification method relies on a comparison across counties within the same state. We account for the possibility that unobservable characteristics that are specific to each state influenced the respective timings of mineral discoveries and political development and may impact violence today in two ways: by including state fixed effects and by accounting for a group structure of the error term at the state level. While state level variation may capture much of the unobserved variation in political development, it may not necessarily capture all the relevant unobserved heterogeneity in mining and political histories across counties: (i) a county may have been affected by the mining history of its immediate neighbors; (ii) mineral resource endowments are not evenly distributed across space for intrinsic geological reasons; (iii) counties located near state boundaries may share some characteristics with counties on the other side of the state border. We present below the various strategies we use to tackle these spatial issues, as well as other threats to identification.

5.2.1. Spatial Correlation. We first use the estimation method pioneered by Conley (1999, 2008) and further developed by Hsiang (2010) to take into account spatial correlation. In columns (1-6) of Table 4, standard errors are adjusted for spatial correlation within a 100-, 300-, and 500-km radius. Standard errors are very similar to those displayed in Table 3. 
TABLE 4. Political and mining history and present-day violent crime: robustness to spatial issues.

\begin{tabular}{|c|c|c|c|c|c|c|c|c|}
\hline Dependent variable: rate of violent $\mathrm{c}$ & $\begin{array}{l}\text { crime per } 100 \\
\text { (1) }\end{array}$ & $\begin{array}{l}0,000 \text { inhabit: } \\
\text { (2) }\end{array}$ & $\begin{array}{l}\text { tants in } 2000 \\
\text { (3) }\end{array}$ & (4) & (5) & (6) & (7) & (8) \\
\hline Post-statehood discoveries & $\begin{array}{c}-79.63^{* *} \\
(34.06)\end{array}$ & $\begin{array}{l}-11.71 \\
(30.39)\end{array}$ & $\begin{array}{c}-79.63^{* *} \\
(36.93)\end{array}$ & $\begin{array}{l}-11.71 \\
(29.84)\end{array}$ & $\begin{array}{c}-79.63^{* * *} \\
(27.14)\end{array}$ & $\begin{array}{l}-11.71 \\
(29.61)\end{array}$ & $\begin{array}{c}-57.70^{* *} \\
(24.11)\end{array}$ & $\begin{array}{c}-1.64 \\
(29.06)\end{array}$ \\
\hline Pre-statehood discoveries & $\begin{array}{c}423.06^{* * * *} \\
(87.03)\end{array}$ & $\begin{array}{c}357.10^{* * * *} \\
(104.95)\end{array}$ & $\begin{array}{c}423.06^{* * * *} \\
(89.84)\end{array}$ & $\begin{array}{c}357.10^{* * * *} \\
(89.08)\end{array}$ & $\begin{array}{c}423.06^{* * * *} \\
(51.34)\end{array}$ & $\begin{array}{c}357.10^{* * * *} \\
(53.57)\end{array}$ & $\begin{array}{c}403.49^{* * * *} \\
(79.55)\end{array}$ & $\begin{array}{c}368.36^{* * * *} \\
(88.47)\end{array}$ \\
\hline State fixed effects & Yes & Yes & Yes & Yes & Yes & Yes & Yes & Yes \\
\hline Geographic controls & & Yes & & Yes & & Yes & & Yes \\
\hline Contemporary controls & & Yes & & Yes & & Yes & & Yes \\
\hline Historical controls & & Yes & & Yes & & Yes & & Yes \\
\hline Spatial correlation adjustment $(\mathrm{km})$ & 100 & 100 & 300 & 300 & 500 & 500 & & \\
\hline Only neighboring counties & & & & & & & Yes & Yes \\
\hline Observations & 3,108 & 2,460 & 3,108 & 2,460 & 3,108 & 2,460 & 1,725 & 1,313 \\
\hline \multirow[t]{2}{*}{$R$-squared } & 0.46 & 0.56 & 0.46 & 0.56 & 0.46 & 0.56 & 0.48 & 0.56 \\
\hline & (9) & (10) & (11) & (12) & (13) & (14) & (15) & (16) \\
\hline Post-statehood discoveries & $\begin{array}{l}-14.11 \\
(22.28)\end{array}$ & $\begin{array}{c}25.95 \\
(31.21)\end{array}$ & $\begin{array}{l}-41.70 \\
(47.87)\end{array}$ & $\begin{array}{l}-14.04 \\
(39.90)\end{array}$ & $\begin{array}{l}-7.06 \\
(83.80)\end{array}$ & $\begin{array}{l}-19.51 \\
(46.55)\end{array}$ & $\begin{array}{l}-31.40 \\
(72.62)\end{array}$ & $\begin{array}{l}-22.85 \\
(53.46)\end{array}$ \\
\hline Pre-statehood discoveries & $\begin{array}{c}324.78^{* * *} \\
(80.71)\end{array}$ & $\begin{array}{c}380.76^{* * *} \\
(90.89)\end{array}$ & $\begin{array}{c}347.22^{* * *} \\
(108.10)\end{array}$ & $\begin{array}{c}373.71^{* * *} \\
(107.61)\end{array}$ & $\begin{array}{c}283.90^{* *} \\
(108.55)\end{array}$ & $\begin{array}{c}370.25^{* * *} \\
(108.31)\end{array}$ & $\begin{array}{c}265.70^{* *} \\
(107.65)\end{array}$ & $\begin{array}{c}383.83^{* * *} \\
\quad(91.55)\end{array}$ \\
\hline State fixed effects & Yes & Yes & & & & & & \\
\hline Geographic controls & & Yes & & Yes & & Yes & & Yes \\
\hline Contemporary controls & & Yes & & Yes & & Yes & & Yes \\
\hline Historical controls & & Yes & & Yes & & Yes & & Yes \\
\hline Only counties with minerals & Yes & Yes & & & & & & \\
\hline Arbitrary state fixed effects & & & Yes & Yes & Yes & Yes & Yes & Yes \\
\hline No. of arbitrary states & & & 245 & 215 & 49 & 49 & 29 & 29 \\
\hline Observations & 849 & 658 & 3,108 & 2,460 & 3,108 & 2,460 & 3,108 & 2,460 \\
\hline$R$-squared & 0.44 & 0.57 & 0.43 & 0.52 & 0.33 & 0.45 & 0.26 & 0.41 \\
\hline
\end{tabular}

Notes: OLS regressions. Each column presents the estimates from a separate regression. The unit of observation is a county. All regressions include a constant term and UCR's county-level coverage indicator. Standard errors are given in parentheses. In columns (1-6), standard errors are computed following Conley $(1999,2008)$ and Hsiang (2010) and using 100-, 300-, and 500-km spatial adjustments. In columns (7-10), White heteroskedastic standard errors are adjusted for clustering at the state level. In columns (11-16), White heteroskedastic standard errors adjusted for clustering at the arbitrary state level. Arbitrary states are cells of 2-, 5-, and 7-degree grids. Violent crimes include murders, aggravated assaults, and other assaults. Pre- and Post-statehood discoveries are the numbers of mineral discoveries per 0.1 square mile that have been discovered before and after political organization, respectively. All regressions include a constant term. Geographic controls: total land area, mean and standard deviation of elevation, agricultural suitability, total length of rivers, a dummy indicating the presence of oil or gas resources, distance to the state's capital, the date at which the county's land was first politically organized, latitude, and longitude. Contemporary controls are measured in 2000: share of population with high school degree, Gini coefficient, population density, per capita income, share of blacks, and ethnic fractionalization. Historical controls: male literacy rate in 1900, population density, share of urban population, share of women, share of non-Whites, per capita farming output and per capita manufacturing output in 1880. See Table A.8 in the Online Appendix for sources and definitions of covariates. ${ }^{* * *} p<0.01,{ }^{* *} p<0.05,{ }^{*} p<0.1$.

5.2.2. Mining Counties and Neighbors. Columns (7) and (8) of Table 4 present estimates obtained when we restrict the sample to counties that are either mining counties or that are immediate neighbors of mining counties. This restricts the sample to around 1,500 counties. Yet, the point estimate of the variable of interest remains of the same order of magnitude. We go further in columns ( 9 ) and (10 by restricting the 
sample to counties that have mineral deposits, that is, we exclude neighboring counties without mineral resources. Even though the sample is further reduced to less than 1,000 county observations, the coefficient associated with pre-statehood discoveries is still negative, statistically significant at the $1 \%$ level and of the same order of magnitude as in Table 3. Meanwhile, the coefficient associated with post-statehood discoveries is not statistically significant and converging toward zero. This confirms that only prestatehood discoveries are associated with violence in a positive, robust and consistent fashion.

5.2.3. Alternative Levels of Fixed Effects. In columns (11-16) of Table 4, we correct for the fact that state borders may not fully capture all the relevant unobserved heterogeneity in counties' mining and political history. We divide the contiguous US territory into arbitrary 2-, 5-, and 7-degree grids and use the resulting groups to construct geographic fixed effects that may better capture unobserved heterogeneity in geological factors or in the progression of the US government. The resulting groups consist of 245,49 , or 29 arbitrary states. The coefficient associated with pre-statehood discoveries declines in magnitude and becomes less precisely estimated the wider the squares of the grid, but remains positive and statistically significant. Again, the coefficient associated with post-statehood discoveries is no longer statistically significant in all of these specifications.

5.2.4. Timing of the Mining Activity. A noteworthy concern regarding our identification strategy is that we compare mineral discoveries that occurred before county political organization to those that occurred anytime since. As displayed in Figure 2 and discussed in Section 3, county political organization was completed by the first years of the 20th century and pre-statehood discoveries thus tend to happen earlier than post-statehood discoveries (as we have already commented, by definition, no pre-statehood discovery can occur after the full territory came under government control). One may thus worry that we do not capture an effect due to the absence or presence of state institutions at the moment of discoveries, but rather simply an effect due to more ancient mining activity. Also, more recent discoveries have of course occurred under completely different technological and economic conditions than earlier ones. Figure 4 helps us address these issues. It displays the estimated coefficients of pre- and post-statehood discoveries as we progressively increase the time window before and after county political organization. We use the specification used in column (5) of Table 3. Each set of estimated coefficients corresponds to a different regression with a different time window. The first set displays the estimated coefficients and standard errors when we consider only discoveries that occurred either 10 years before or 10 years after political organization. The second set displays the same statistics when we consider all the discoveries that occur within 20 years of county political organization. And so on and so forth until 100 years. The coefficient associated with pre-statehood discoveries is remarkably stable as we expand this time window. In other words, the positive coefficient estimated for pre-statehood discoveries is mainly driven by discoveries that occurred up to 10 years before administrative organization 


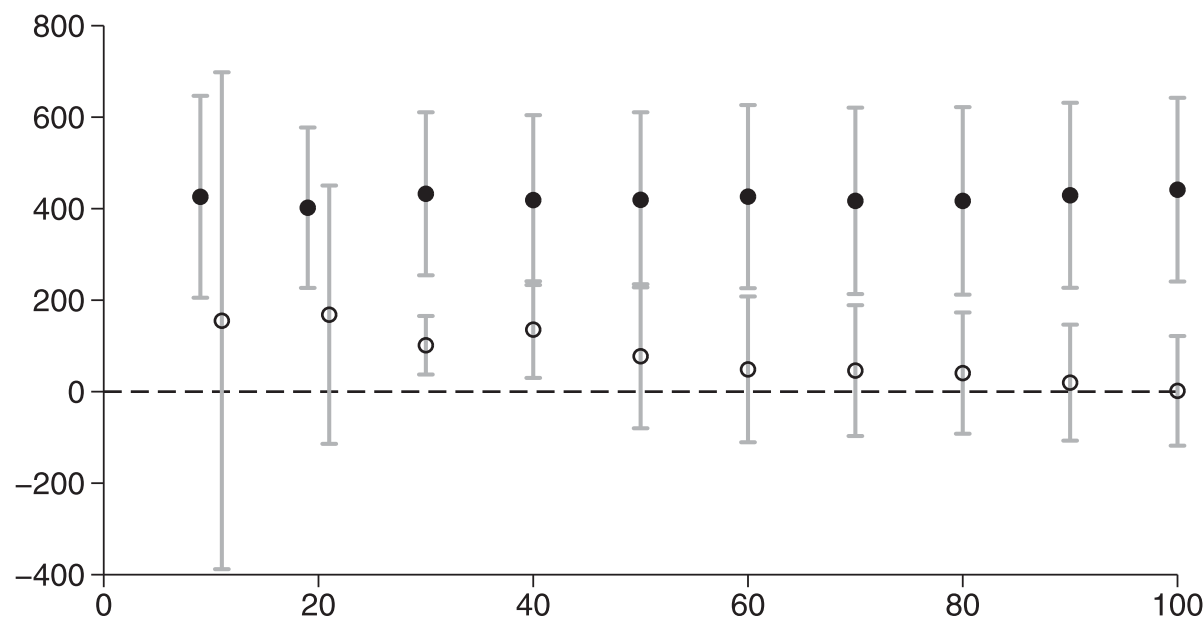

Size of observation window around organization of the land (years)

- Coefficient of pre-statehood discoveries

- Coefficient of post-statehood discoveries $95 \%$ confidence intervals

FIGURE 4. Varying the observation window for discoveries. The figure plots the estimated coefficients of pre- and post-statehood mineral discoveries when varying the time window within which we observe discoveries around the date of political organization. Estimates are those obtained using the specification displayed in column (5) of Table 3. Estimates for the 10- and 20-year windows have been shifted horizontally for aesthetic considerations.

of the land. Further expanding the observation window to include older discoveries does not change the estimated coefficient. By contrast, the forward expansion of the window to take into account more recent discoveries increases the precision of the non-significant coefficient of post-statehood discoveries, which clearly becomes zero.

5.2.5. Outliers. Table A.6, presented in the Online Appendix, displays different approaches that allow us to ensure that our estimates of interest are not driven by outlying counties. As shown by the estimated coefficients presented in columns (1) and (2), our estimates are not affected by a log-transformation of the dependent variable. In columns (3) and (4), and (5) and (6), we exclude counties that belong to the bottom and top $5 \%$ of the distributions of violence and mines, respectively. This allows us to sequentially remove potential outliers in terms of the dependent and the independent variables. We combine both approaches by excluding counties that meet any of these two criteria in columns (7) and (8). Our estimate of interest is not substantially affected. Columns (9-12) convey a similar message by excluding counties for which the overall model performs poorly and produces residuals that exceed 2 and 3 standard deviations. 
5.2.6. Randomly Allocated Discoveries. As an additional illustration of our identification strategy, we undertake two placebo tests portrayed by Figure A.1 in the Online Appendix. The placebo tests consist of randomly reallocating mineral resources discoveries across either time or space and reestimating the relation we are interested in. Randomization across time is achieved by randomizing the share of minerals discovered in a county pre- or post-statehood, taking the total number of mineral discoveries in the county. Randomization across space is achieved by randomly allocating mineral discoveries to counties, keeping constant the overall distribution of minerals across countries. We implemented each approach 1,000 times. Hardly any of the allocations we created managed to reproduce the coefficient of pre-statehood discoveries estimated on observed data.

\subsection{Interpretation}

We find robust evidence that prevailing violence today is influenced by the specific circumstances of mineral discoveries in the United States. We find that counties where minerals were discovered before the state was established experience higher interpersonal violence, and the magnitude of the effect is substantial.

These results hold even though we control throughout for state-level fixed effects, which absorb much of the variation in the quality of formal institutions across the United States. The remaining variation in homicide rates is suggestive of the presence of differences in cultural norms that sustain the use of interpersonal violence.

Yet, we cannot fully rule out that institutions vary at a very local level, potentially even as a result of differences in cultural norms. Indeed, if cultural norms toward violence are different, even similar formal institutions may be enforced and implemented in a different way, which might in turn reinforce cultural norms. For example, in areas where social norms are more encouraging and tolerant of violence, popular juries will be more lenient toward violent offenders, and the anticipation of lighter sentences may encourage more violence. In fact, we view cultural and institutional persistence as two intrinsically linked processes that reinforce one another.

Overall, the interpretation of our results is that where formal institutions were absent at the time of mineral discoveries, interpersonal violence was a very valuable strategy to defend and enforce property rights over minerals. As a result, high levels of violence prevailed, and both attitudes toward the use of violence and the tendency to resort to violence shifted. Such a culture of violence also potentially affected how formal institutions were enforced. These areas were subsequently locked in a culturalinstitutional equilibrium characterized by a high level of violence, despite subsequent changes to the quality of formal institutions.

\section{Conclusion}

This work documents the negative short- and long-run consequences of mineral discoveries in the context of weak polities. It uncovers the existence of a homicide 
resource curse, which is conditional on the quality of initial formal institutions. In areas of the United States where mineral discoveries occurred before the state was established, higher levels of interpersonal violence prevailed historically and have persisted until today.

We argue and document that there is no systematic association between mineral discoveries and state development at the local level we consider in this paper. Furthermore, we find that our results are driven by discoveries that occur within 10 years of state incorporation. This suggests that a relatively short-term and quasiexogenous variation in the institutional environment can lead to large and persistent differences in subsequent cultural and institutional development. The implications are substantial, in light of a growing body of evidence on the effects of cultural norms and institutions on economic growth and development.

\section{References}

Acemoglu, Daron, Simon Johnson, and A. Robinson James (2001). "The Colonial Origins of Comparative Development: An Empirical Investigation". American Economic Review, 91(5), 1369-1401.

Alesina, Alberto, Paola Giuliano, and Nathan Nunn (2013). "On the Origins of Gender Roles: Women and the Plough." The Quarterly Journal of Economics, 128, 469-530.

Anderson Terry, L. and J. Hill Peter (2004). The Not So Wild, Wild West: Property Rights on the Frontier. Stanford University Press.

Aragón Fernando, M. and Pablo Rud Juan (2013). "Natural Resources and Local Communities: Evidence from a Peruvian Gold Mine." American Economic Journal: Economic Policy, 5, 1-25.

Belloc, Marianna and Samuel Bowles (2013). "The Persistence of Inferior Cultural-Institutional Conventions". American Economic Review, 103(3), 93-98.

Berman, Nicolas, Mathieu Couttenier, Dominic Rohner, and Mathias Thoenig (2015). "This Mine is Mine! How Minerals Fuel Conflicts in Africa." CESifo Working Paper Series 5409, CESifo Group Munich.

Bisin, Alberto and Thierry Verdier (2015). "On the Joint Evolution of Culture and Institutions." Working paper, NYU and PSE.

Brollo, Fernanda, Tommaso Nannicini, Roberto Perotti, and Guido Tabellini (2013). "The Political Resource Curse". American Economic Review, 103(5), 1759-96.

Buonanno, Paolo, Ruben Durante, Giovanni Prarolo, and Paolo Vanin (2015). "Poor Institutions, Rich Mines: Resource Curse in the Origins of the Sicilian Mafia." The Economic Journal, 125, F175-F202.

Castillo Juan, Camilo, Daniel Mejía, and Pascual Restrepo (2014). "Scarcity without Leviathan: The Violent Effects of Cocaine Supply Shortages in the Mexican Drug War.” Working Paper 356, Center for Global Development. Washington, DC: Center for Global Development.

Chassang, Sylvain and Gerard Padró i Miquel (2010). "Conflict and Deterrence under Strategic Risk." The Quarterly Journal of Economics, 125, 1821-1858.

Clay, Karen and Randall Jones (2008). "Migrating to Riches? Evidence from the California Gold Rush.” The Journal of Economic History, 68, 997-1027.

Clay, Karen and Gavin Wright (2011). "Gold Rush Legacy: American Minerals and the Knowledge Economy.” In Property in Land and Other Resources, edited by Daniel Cole and Elinor Ostrom. Cambridge: Lincoln Land Institute Press.

Conley Timothy, G. (1999). "GMM Estimation with Cross Sectional Dependence." Journal of Econometrics, 92, 1-45. 
Conley Timothy, G. (2008). "Spatial Econometrics." In The New Palgrave Dictionary of Economics, edited by Steven N. Durlauf and Lawrence E. Blume. London: Palgrave Macmillan, pp. 741-747.

David Paul, A. and Gavin Wright (1995). "The Origins of American Resource Abundance." Research Memoranda 017. Maastricht: MERIT, Maastricht Economic Research Institute on Innovation and Technology.

Davis Lance, E., A. Easterlin Richard, and N. Parker William (1972). American Economic Growth: An Economist's History of the United States. New York: Harper \& Row.

Dell, Melissa (2010). "The Persistent Effects of Peru's Mining Mita." Econometrica, 78, 1863-1903.

Draca, Mirko, Stephen Machin, and Robert Witt (2011). "Panic on the Streets of London: Police, Crime, and the July 2005 Terror Attacks". American Economic Review, 101(5), $2157-81$.

Dube, Oeindrila and F. Vargas Juan (2013). "Commodity Price Shocks and Civil Conflict: Evidence from Colombia." The Review of Economic Studies, 80, 1384-1421.

Durante, Ruben (2009). "Risk, Cooperation and the Economic Origins of Social Trust: An Empirical Investigation.” MPRA Paper 25887, University Library of Munich, Germany.

Elias, Norbert (1994). The Civilizing Process. Oxford, UK: Blackwell Publishers.

Engerman Stanley, L. and L. Sokoloff Kenneth (1997). "Factor Endowments, Institutions, and Differential Paths of Growth Among New World Economies: A view from Economic Historians of the United States." In How Latin America Fell Behind, edited by Stephen Harber. Stanford University Press, pp. 260-304.

Engerman Stanley, L. and L. Sokoloff Kenneth (2002). "Factor Endowments, Inequality, and Paths of Development Among New World Economics." Economia, 3, 41-109.

Ghosh, Sambuddha, Gabriele Gratton, and Caixia Shen (2013). "Terrorism: A Model of Intimidation." Working Papers 2015 ECON 7, UNSW.

Gonzalez Francisco, M. (2012). "The Use of Coercion in Society: Insecure Property Rights, Conflict and Economic Backwardness." In Oxford Handbook of the Economics of Peace and Conflict, edited by R Michelle. Garfinkel and Stergios Skaperdas. Oxford University Press.

Grosjean, Pauline (2014). "A History of Violence: The Culture of Honor and Homicide in the US South." Journal of the European Economic Association, 12, 1285-1316.

Guiso, Luigi, Paola Sapienza, and Luigi Zingales (2008). "Alfred Marshall Lecture Social Capital as Good Culture." Journal of the European Economic Association, 6, 295-320.

Haines Michael, R. and Inter-University Consortium for PoliticalSocial Research (2010). Historical, Demographic, Economic, and Social Data: The United States, 1790-2002. Ann Arbor, MI: InterUniversity Consortium for Political and Social Research.

Hobbes, Thomas (1651). Leviathan. Printed for Andrew Crooke, at the Green Dragon in St Paul's Churchyard.

Hsiang Solomon, M. (2010). "Temperatures and Cyclones Strongly Associated with Economic Production in the Caribbean and Central America." Proceedings of the National Academy of Sciences, 107, 15367-15372.

Kessler Daniel, P and D. Levitt Steven (1999). "Using Sentence Enhancements to Distinguish between Deterrence and Incapacitation." Journal of Law and Economics, 42, 343-63.

Lei, Yu-Hsiang and Guy Michaels (2014). "Do Giant Oilfield Discoveries Fuel Internal Armed Conflicts?" Journal of Development Economics, 110, 139-157.

Levitt Steven, D. (1997). "Using Electoral Cycles in Police Hiring to Estimate the Effect of Police on Crime". American Economic Review, 87(3), 270-90.

McKanna Clare, V. (1997). Homicide, Race, and Justice in the American West, 1880-1920. Tucson: University of Arizona Press.

Mehlum, Halvor, Ove Moene Karl, and Ragnar Torvik (2006). "Institutions and the Resource Curse." Economic Journal, 116, 1-20.

Mullen Kevin, J. (2005). Dangerous Strangers: Minority Newcomers and Criminal Violence in the Urban West, 1850-2000. New York: Palgrave Macmillan.

Nisbett Richard, E. and Dov Cohen (1996). Culture of Honor: The Psychology of Violence in the South. Boulder, Colorado: Westview Press.

Nunn, Nathan and Leonard Wantchekon (2011). "The Slave Trade and the Origins of Mistrust in Africa”. American Economic Review, 101(7), 3221-52. 
Oster, Emily (2015). "Unobservable Selection and Coefficient Stability: Theory and Evidence." Manuscript.

Pinker, Steven (2011). The Better Angels of Our Nature: Why Violence Has Declined. New York: Viking.

Rajan Raghuram, G. (2009). "Rent Preservation and the Persistence of Underdevelopment." American Economic Journal: Macroeconomics, 1, 178-218.

Restrepo, Pascual (2015). "The Mounties and the Origins of Peace in the Canadian Prairies." Working paper, MIT.

Roth, Randolph (2009). American Homicide. Harvard University Press: The Belknap Press.

Raúl, Sánchez de la Sierra (2015). "On the Origins of States: Stationary Bandits and Taxation in Eastern Congo." HiCN Working Papers 194, Households in Conflict Network. Brighton: Househomds in Conflict Network.

Silverman, Dan (2004). "Street Crime and Street Culture." International Economic Review, 45, 761-786.

Skaperdas, Stergios (1992). "Cooperation, Conflict, and Power in the Absence of Property Rights". American Economic Review, 82(4), 720-39.

Tabellini, Guido (2008). "The Scope of Cooperation: Values and Incentives.” The Quarterly Journal of Economics, 123, 905-950.

Torvik, Ragnar (2009). "Why Do Some Resource-Abundant Countries Succeed While Others Do Not?" Oxford Review of Economic Policy, 25, 241-256.

Wright, Gavin (1990). "The Origins of American Industrial Success, 1879-1940". American Economic Review, 80(4), 651-68.

Young Peyton, H. (1998). Individual Strategy and Social Structure: An Evolutionary Theory of Institutions. Princeton University Press.

\section{Supplementary Data}

Supplementary data are available at JEEA online. 